\title{
Prevention and treatment of oral mucositis in patients receiving chemotherapy
}

\author{
Carlos Alvariño-Martín ${ }^{1}$, Maria-Gracia Sarrión-Pérez ${ }^{2}$
}

\footnotetext{
${ }^{1}$ Dentistry, Master of Oral Medicine and Oral Surgery, Faculty of Medicine and Dentistry, University of Valencia, Spain

${ }^{2}$ Adjunt Professor of the Department of Stomatology, Faculty of Medicine and Dentistry, University of Valencia, Spain
}

\author{
Correspondence: \\ Clínica Odontológica, \\ Medicina Bucal, \\ Gascó Oliag 1, \\ 46020, Valencia, Spain \\ alvarinomartin.carlos@gmail.com
}

Received: 30/09/2013

Accepted: $21 / 11 / 2013$

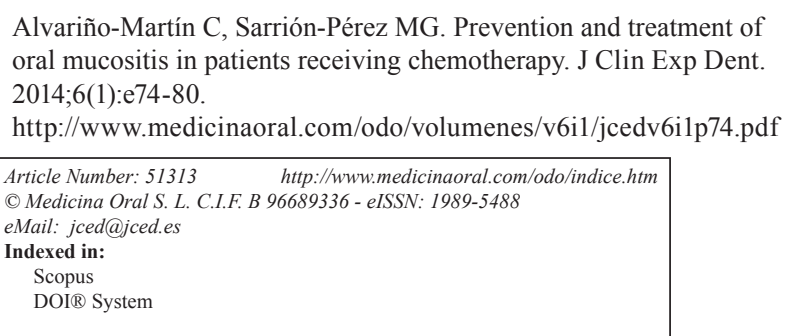

\begin{abstract}
Oral mucositis is one of the most common side effects of cancer treatment (chemotherapy and/or radiotherapy). It is an inflammatory process that affects the mucosa of the oral cavity, giving rise to erythematous areas in combination with ulcers that can reach a large size. The true importance of oral mucositis is the complications it causes - fundamentally intense pain associated to the oral ulcers, and the risk of overinfection. This in turn may require reduction or even suspension of the antineoplastic treatment, with the risk of seriously worsening the patient prognosis. This points to the importance of establishing therapeutic tools of use in the prevention and/or treatment of mucositis. The present study offers a literature review of all the articles published over the last 10 years referred to the prevention and/or treatment of oral mucositis associated to chemotherapy.
\end{abstract}

Key words: Oral mucositis, management, prevention, treatment, chemotherapy.

\section{Introduction}

Oral mucositis $(\mathrm{OM})$ is defined as inflammation of the mucosa oral cavity, and is clinically characterized by the presence of erythematous areas that subsequently merge with ulcerations (1).

Oral mucositis is caused by destruction of the oral mucosal epithelium and suppression of its growth secondary to antineoplastic treatment in the form of chemotherapeutic drug substances or radiotherapy $(2,3)$.

The pathogenesis of mucositis is currently based on a model comprising five biological phases, developed by Sonis et al. (4): initiation, signaling, signal amplification, ulceration and healing.

The frequency of mucositis and its severity are fundamentally dependent upon the type, duration and dose of chemotherapy used (5). In this sense, bone marrowsuppressing (myeloablative) chemotherapy is associated with a mucositis risk of $60-100 \%(4,6,7)$, while the combination of chemotherapy and radiotherapy implies a risk of almost $100 \%$ (3).

The clinical manifestations of OM become visible 4-5 days after the start of chemotherapy, with the detection of erythematous areas in the oral cavity. After 7-10 days ulcers start to develop; these gradually grow in number and size, and tend to merge, forming large ulcerated zones $(4,8)$. The ulcers are generally of scant depth, with a necrotic base, and the margins show little inflammatory infiltration. These lesions are very painful, cause swallowing problems, and take about two weeks to heal once chemotherapy has been suspended $(3,4)$. 
A number of OM classification and staging systems have been described (9), though the most widely used is that proposed by the World Health Organization (WHO)(Table 1).

Table 1. Oral mucositis classification - staging system proposed by the World Health Organization (WHO).

\begin{tabular}{|l|l|}
\hline Grade & Clinical manifestations \\
\hline 0 & No subjective or objective evidence of mucositis \\
\hline I & Pain with or without erythema, without ulcers \\
\hline II & Erythema and ulceration. The patient can swallow solids \\
\hline III & $\begin{array}{l}\text { Erythema and ulceration. The patient can swallow liquids, } \\
\text { but not solids }\end{array}$ \\
\hline IV & $\begin{array}{l}\text { Erythema and ulceration. The patient cannot swallow liq- } \\
\text { uids or solids }\end{array}$ \\
\hline
\end{tabular}

Oral mucositis causes many complications, ranging from speech and swallowing difficulties to intense pain and ulcer overinfection, which may lead to systemic infection (bacteremia or fungemia) - posing a threat to patient life and requiring admission to hospital, with the increased economic costs this implies. These complications may require reduction or even suspension of the antineoplastic treatment, with the risk of seriously worsening the patient prognosis $(3,5,9,10)$.

In relation to $\mathrm{OM}$ secondary to chemotherapy, many studies have evaluated the efficacy of different interventions designed to prevent and/or treat the disease.

The present review examines those therapeutic tools that have been shown to be useful in the prevention or treatment of OM.

\section{Material and Methods}

A literature search was made of the PubMed, Cochrane and Scopus databases, using different combinations of the following key words: "oral mucositis", "treatment", "prevention", "management", "chemotherapy". These key words in turn were validated by the "Mesh" and "DeCS" dictionaries, and the boolean operator "AND" was used to relate them in each search. The limits established for inclusion of the articles in the study were: publications in English, studies in humans, and articles published over the last 10 years [2002-2012].

Following application of the filters, we identified 169 articles. Many of them were discarded, since they only focused on OM associated to radiotherapy. We finally selected only those publications affording a scientific evidence level of I-II according to the classification proposed by the National Health and Medical Research Council of Australia (11), and those articles which while not constituting systematic reviews did specify the material and methods used. A total of 44 articles were thus finally obtained.

\section{Results}

The main strategies and drugs described in the literature over the last 10 years designed to prevent and/or treat OM secondary to chemotherapy are the following:

- Oral hygiene protocols

Oral care can reduce the presence of microbial flora, the pain and bleeding, and prevent infections. Likewise, good oral health reduces the risk of dental complications (6). However, the effectiveness of oral hygiene in preventing the appearance of $\mathrm{OM}$ or in reducing its severity has been placed in doubt, since the studies published to date offer contradictory results $(12,13)$.

\section{- Chlorhexidine digluconate}

The antimicrobial agent most widely studied in the management of $\mathrm{OM}$ is chlorhexidine, used in oral rinses at concentrations of $0.12-0.2 \%$, since it has been suggested to be useful in maintaining improved oral hygiene and in reducing mucosal inflammation (1). However, the results obtained in the different clinical trials are inconclusive $(1,2,14)$.

- Cytoprotective agents

- Amifostine:

Amifostine (Ethyol $\left.{ }^{\circledR}\right)$ is an organic thiophosphate believed to act as a reactive oxygen species (ROS) scavenger. In this context, ROS are known to play a key role in the etiopathogenesis of OM $(2,15)$.

In this review we have found only one randomized, controlled clinical trial (RCCT) published in the last 10 years, which reported no benefits with the preventive use of amifostine in patients subjected to chemotherapyradiotherapy (16).

- Sucralfate:

Sucralfate is a drug with cytoprotective properties used in the treatment of peptic ulcers (1). Many studies have evaluated its effectiveness in irradiated patients, with very dissimilar results. In contrast, it is little used in patients subjected to chemotherapy. Indeed, over the last decade, only one RCCT has examined the effect of sucralfate rinses in patients subjected to chemotherapy with 5-fluorouracil (5-FU)(17), and its results indicate no effectiveness in the prevention of OM.

- Glutamine:

Glutamine is one of the most abundant amino acids in the body, where it is involved in numerous beneficial functions. It could be of help in the prevention and treatment of OM, since it plays a fundamental role in regulation of the redox potential, and some studies have even suggested that it exerts a favorable effect by reducing the production of proinflammatory cytokines (10). In the last 10 years three RCCTs (18-20) have evaluated the preventive effects of glutamine in patients scheduled for chemotherapy. Two of them obtained results supporting the use of glutamine, though the samples sizes were relatively small (16-32 subjects)(19,20). In contrast, the study published by Pytlik et al. (18) not only found glu- 
tamine to be ineffective in the prevention of OM, but also suggested that it might worsen OM and even increase the risk of tumor relapse.

\section{- Allopurinol}

Allopurinol has been used on an experimental basis for both the prevention and treatment of mucositis induced by fluorouracil. Its activity is based on two different mechanisms: the elimination of ROS, and specific inhibition of the activation of fluorouracil.

The clinical trial conducted by Panahi et al. (21) found allopurinol rinses to offer little efficacy in preventing $\mathrm{OM}$ in patients subjected to chemotherapy with 5-FU.

\section{- Cryotherapy}

The application of ice within the oral cavity causes local vasoconstriction, which in turn lessens blood flow to the oral mucosa and reduces the amount of cytotoxic medication reaching the cells - thereby lowering the incidence of mucositis (22).

This technique involves placing ice cubes in the mouth 5 minutes before starting the chemotherapy cycle, and keeping them in the mouth for 30-45 minutes.

Cryotherapy for the prevention of OM has been studied in application to different chemotherapy regimens (Table 2). In this context, Sorensen et al. (23), Papadeas et al. (24) and Nikoletti et al. (25) conducted clinical trials in patients treated with 5-FU; Gori et al. (26) studied patients treated with methotrexate; and Lilleby et al. (27) and Svanberg et al. (28) investigated conditioning therapies with melphalan prior to hematopoietic stem cell transplantation (HSCT). The results showed cryotherapy to be effective in the prevention of OM when used with chemotherapeutic agents having a short plasma half-life, such as bolus doses of 5-fluorouracil and melphalan. In contrast, drugs with a half-life of between 3-15 hours, such as methotrexate, yielded inconclusive results.

- Growth factors

Growth factors are proteins that stimulate cell growth, proliferation and differentiation. Within this family of proteins, the growth factors most widely investigated in the prevention and treatment of $\mathrm{OM}$ are palifermin (keratinocyte growth factor) and the colony-stimulating factors (29).

Palifermin (Kepivance $囚)$ is a recombinant human keratinocyte growth factor that stimulates epithelial cell proliferation and increases the thickness of the non-keratinized layers of the oral and gastrointestinal mucosa (29). In this review we identified 8 RCCTs (Table 3 ) in which the efficacy of palifermin in the prevention of OM indu-

Table 2. Studies on cryotherapy for the prevention of oral mucositis.

\begin{tabular}{|l|l|l|l|}
\hline Author & No. patients & Drug (CT) & Results \\
\hline Sorensen et al. (23) & 225 & 5-FU & Effective \\
\hline Papadeas et al. (24) & 76 & 5-FU & Effective \\
\hline Nikoletti et al. (25) & 67 & 5-FU & Effective \\
\hline Gori et al. (26) & 130 & Methotrexate & Ineffective \\
\hline Lilleby et al. (27) & 40 & Melphalan (conditioning prior to HSCT) & Effective \\
\hline Svanberg et al. (28) & 80 & Melfalan (conditioning prior to HSCT) & Effective \\
\hline
\end{tabular}

* CT: chemotherapy; HSCT: hematopoietic stem cell transplantation

Table 3. Studies of palifermin in the prevention of oral mucositis.

\begin{tabular}{|c|c|c|c|c|c|}
\hline Author & $\begin{array}{l}\text { Palifermin } \\
\text { dose }\end{array}$ & $\begin{array}{l}\text { No. } \\
\text { patients }\end{array}$ & Type of cancer & Treatment & Results \\
\hline $\begin{array}{l}\text { Meropol et al. } \\
\text { (35) } 2003\end{array}$ & $\begin{array}{l}1,10,20,40,60 \\
\text { or } 80 \mu \mathrm{g} / \mathrm{kg} / \mathrm{d}\end{array}$ & 81 & $\begin{array}{l}\text { Metastatic colorectal } \\
\text { cancer }\end{array}$ & CT & Effective \\
\hline $\begin{array}{l}\text { Spielberger et } \\
\text { al. (30) } 2004\end{array}$ & $60 \mu \mathrm{g} / \mathrm{kg} / \mathrm{d}$ & 212 & $\begin{array}{l}\text { Lymphoma, leukemia } \\
\text { or multiple myeloma }\end{array}$ & $\begin{array}{l}\text { Conditioning }(\mathrm{CT}+\mathrm{RT}) \\
\text { prior to autologous } \\
\text { HSCT }\end{array}$ & Effective \\
\hline $\begin{array}{l}\text { Blazar et al. } \\
\text { (31) } 2006\end{array}$ & $\begin{array}{l}40 \text { or } 60 \mu \mathrm{g} / \\
\mathrm{kg} / \mathrm{d}\end{array}$ & 100 & $\begin{array}{l}\text { Lymphoma, leukemia } \\
\text { or myelodysplastic } \\
\text { syndrome }\end{array}$ & $\begin{array}{l}\text { Conditioning (2 options): } \\
\text { A: CT }+ \text { RT } \\
\text { B: CT } \\
\text { Prior to allogenic HSCT }\end{array}$ & $\begin{array}{l}\text { Effective } \\
\text { in patients } \\
\text { with adju- } \\
\text { vant RT }\end{array}$ \\
\hline $\begin{array}{l}\text { Rosen et al. } \\
\text { (36) } 2006\end{array}$ & $40 \mu \mathrm{g} / \mathrm{kg} / \mathrm{d}$ & 64 & $\begin{array}{l}\text { Solid tumors (colon } \\
\text { and rectum) }\end{array}$ & CT & Effective \\
\hline $\begin{array}{l}\text { Brizel et al. } \\
\text { (32) } 2008\end{array}$ & $60 \mu \mathrm{g}$ & 99 & Head and neck cancer & $\mathrm{RT}+\mathrm{CT}$ & Ineffective \\
\hline $\begin{array}{l}\text { Vadhan-Raj et } \\
\text { al. (37) } 2010\end{array}$ & $180 \mu \mathrm{g} / \mathrm{kg} / \mathrm{d}$ & 48 & Sarcoma & CT & Effective \\
\hline $\begin{array}{l}\text { Henke et al. } \\
\text { (33) } 2011\end{array}$ & $120 \mu \mathrm{g} / \mathrm{kg} / \mathrm{wk}$ & 186 & Head and neck cancer & $\mathrm{RT}+\mathrm{CT}$ & Effective \\
\hline $\begin{array}{l}\text { Le et al. (34) } \\
2011\end{array}$ & $180 \mu \mathrm{g} / \mathrm{kg} / \mathrm{wk}$ & 188 & Head and neck cancer & $\mathrm{RT}+\mathrm{CT}$ & Effective \\
\hline
\end{tabular}

*CT: chemotherapy; RT: radiotherapy; HSCT: hematopoietic stem cell transplantation 
ced by chemotherapy has been studied (30-37).

Although the results have been promising in almost all of these trials, the publication with the strongest methodological design was that carried out by Spielberger et al. (30), who found palifermin to be very effective in the prevention of oral mucositis in patients scheduled for conditioning treatment (chemotherapy and total body irradiation) prior to hematopoietic stem cell transplantation.

In contrast, the results obtained are not so good when the patients are subjected to conditioning treatment with chemotherapy but without total body irradiation prior to allogenic stem cell transplantation (31).

Regarding patients with head and neck cancer subjected to chemotherapy - radiotherapy, the results obtained by Brizel et al. (32) reveal no efficacy on the part of palifermin, in contrast to the data obtained by the studies published in 2011 by Henke et al. (33) and Le et al. (34), in which palifermin was seen to significantly reduce the incidence of severe OM. The explanation for these conflicting results may be the possibly insufficient palifermin dose (60 $\mu \mathrm{g}$ in a single dose) administered in the study of Brizel et al.

The studies published by Meropol et al. (35), Rosen et al. (36) and Vadhan-Raj et al. (37) support the efficacy of palifermin in patients with solid tumors (metastatic colorectal cancer or sarcoma) subjected to chemotherapy, though it must be noted that their data may involve bias (masking difficulties, small sample size, etc.).

Colony-stimulating factors are glycoproteins produced by a broad range of human cells, some of which are of hematopoietic lineage, such as fibroblasts, endothelial cells and immune system cells (macrophages, $\mathrm{T}$ cells). Interest has focused mainly on granulocyte colony-stimulating factor (G-CSF) and granulocyte-macrophage colony-stimulating factor (GM-CSF). Both act at two levels in the prevention and treatment of mucositis: at central level by stimulating bone marrow recovery, and at peripheral level by promoting keratinocyte production $(3,29)$.
There have been no RCCTs in the last decade on the preventive or therapeutic efficacy of G-CSF in application to mucositis. In relation to GM-CSF, the studies of Dazzi et al. (38) and Valcarcel et al. (39) indicate scant efficacy on the part of oral rinses containing GM-CSF in preventing and treating mucositis.

- Low-ievel laser therapy (LLLT)

It is known that radiation, at certain wavelengths, may exert beneficial effects upon cells. Phototherapy, including low-level laser therapy (LLLT), is based on the interaction of low energy density light (a few $\mathrm{J} / \mathrm{cm}^{2}$ ) with cells and tissues, without the generation of thermal effects. It is believed that this type of therapy, with wavelengths of between $600-900 \mathrm{~nm}$, could exert a biomodulating effect upon cells and tissues secondary to absorption of the light by endogenous photoreceptors $(7,40)$. The activation of these photoreceptors may modify cell metabolism depending on the light energy dose delivered. Accordingly, low energy doses could act by reducing the production of ROS, and also by stimulating protein synthesis with the

facilitation of tissue repair. Likewise, they may exert an antiinflammatory effect by reducing prostaglandin synthesis (7).

In recent years different studies have been made on the use of LLLT for the prevention and treatment of oral mucositis (Table 4).

The studies of Schubert et al. (41) and Antunes et al. (42) have demonstrated the efficacy of LLLT at wavelengths of 650-660 nm in the prevention of OM among patients subjected to conditioning with chemotherapy or chemotherapy - radiotherapy prior to HSCT.

However, the study published by Cruz et al. (43) revealed no benefits with the preventive use of LLLT in patients subjected to different chemotherapy regimens.

The results likewise have not been encouraging in patients with head and neck cancer scheduled for chemotherapy - radiotherapy (44).

In assessing the efficacy of LLLT in the treatment of established mucositis, mention must be made of the studies

Table 4. Studies of low-level laser therapy in the prevention and treatment of oral mucositis.

\begin{tabular}{|l|l|l|l|l|}
\hline Author & No. patients & CT scheme & Therapeutic objective & Results \\
\hline Schubert et al. (41) & 70 & $\begin{array}{l}\text { Conditioning (CT and/ } \\
\text { or RT) prior to HSCT }\end{array}$ & Prevention of OM & Effective \\
\hline Antunes et al. (42) & 38 & $\begin{array}{l}\text { Conditioning (CT and/ } \\
\text { or RT) prior to HSCT }\end{array}$ & Prevention of OM & Effective \\
\hline Cruz et al. (43) & 60 & CT & Prevention of OM & Ineffective \\
\hline $\begin{array}{l}\text { Gouvêa de Lima et } \\
\text { al. (44) }\end{array}$ & 75 & $\begin{array}{l}\text { CT+RT (head and } \\
\text { neck cancer) }\end{array}$ & Prevention of OM & Ineffective \\
\hline $\begin{array}{l}\text { Genot-Klastersky et } \\
\text { al. (45) }\end{array}$ & 36 & $\begin{array}{l}\text { Conditioning (CT) } \\
\text { prior to HSCT }\end{array}$ & Treatment of OM & Effective \\
\hline Kuhn et al. (46) & 21 & $\begin{array}{l}\text { Conditioning (CT and/ } \\
\text { or RT) prior to HSCT }\end{array}$ & Treatment of OM & Effective \\
\hline
\end{tabular}

*CT: chemotherapy; RT: radiotherapy; HSCT: hematopoietic stem cell transplantation 
carried out by Genot-Klastersky et al. (45) and Kuhn et al. (46). Both reported a clear decrease in the duration of OM in the patients treated with LLLT.

\section{Discussion}

On the basis of the data afforded by the reviewed studies, an analysis can be made of their conclusions, comparing them with those of other literature reviews and metaanalyses published over the last 10 years.

Worthington et al. (47) published a systematic review in the Cochrane database referred to randomized studies on the prevention of mucositis, with the inclusion of a total of 131 trials assessing 43 different interventions. Based on all these studies, the authors firstly concluded that only cryotherapy and palifermin offer some evidence of benefit. Secondly, very weak evidence of benefit was observed for 8 interventions (aloe vera, amifostine, glutamine, G-CSF, honey, laser, polymyxin / tobramycin / amphotericin (PTA) paste or tablets, and sucralfate). On the other hand, they pointed out that all 10 interventions were considered to imply a high or uncertain risk of bias.

Regarding the metaanalysis on the treatment of mucositis published by Clarkson et al. (48) in the same database, the authors found that of the 21 interventions included (32 trials), only LLLT showed a certain effectiveness in the treatment of mucositis, based on two studies with no high risk of bias in the results obtained.

It must be underscored that these reviews included interventions aimed at preventing and treating $\mathrm{OM}$ induced both by chemotherapy and radiotherapy, while our review focused on the techniques used to prevent or treat mucositis induced only by chemotherapy or by combinations of chemotherapy - radiotherapy. On the other hand, and since there are many chemotherapy regimens, we were interested in specifying not only which interventions show some scientific evidence of efficacy, but also in application to which kind of chemotherapy regimen. Of all the interventions analyzed in our review, only three showed significant efficacy in preventing OM (cryotherapy, palifermin and LLLT), while only one intervention proved effective in the treatment of established mucositis (LLLT).

Cryotherapy has been one of the most widely investigated interventions over the years. As we have seen, it is very effective in preventing $\mathrm{OM}$ in patients scheduled for chemotherapy with antineoplastic drugs that have a short plasma half-life, such as bolus doses of 5-fluorouracil or the administration of high-dose melphalan prior to HSCT.

Another treatment supported by important scientific evidence is palifermin (keratinocyte growth factor). Indeed, it is the only drug approved to date by the United States Food and Drug Administration (FDA) for the prevention of oral mucositis in patients subjected to myeloablative treatment with chemotherapy and radiotherapy prior to HSCT. The clinical trials show the ideal approach in patients of this kind to be the intravenous administration of $60 \mu \mathrm{g} / \mathrm{kg}$ of palifermin a day during three consecutive days before the start of conditioning, with a further three days of administration after stem cell transplantation (days 0,1 and 2).

In 2011, the studies carried out by Henke et al. (33) and Le et al. (34) indicated that palifermin could also be effective for the prevention of OM in head and neck cancer patients subjected to radiotherapy (total dose 60$66 \mathrm{~Gy})$ together with chemotherapy (cisplatin).

Interest in the development of radiation techniques for the prevention and treatment of OM has grown in recent years. To date, low-level laser therapy (LLLT) is the technique that has shown the greatest effectiveness. Many clinical trials have evaluated the preventive efficacy of LLLT, and the best results have been obtained when it is used in patients subjected to conditioning regimens prior to HSCT.

According to the review published by Clarkson et al. (48), LLLT is the only technique to have shown certain evidence of efficacy in the treatment of established mucositis. This is the conclusion drawn from the clinical trials carried out by Genot-Klastersky et al. (45) and Kuhn et al. (46), in which patients with OM secondary to conditioning prior to HSCT recovered earlier from their oral lesions when laser therapy was applied. Nevertheless, it must be underscored that these are only two studies, and moreover involve few patients (57 in total). The body of evidence for this type of intervention is therefore smaller than in the above cases.

It is also important to emphasize the importance of correct oral hygiene in cancer patients. Although there is no scientific evidence demonstrating the efficacy of oral hygiene protocols in the prevention and treatment of mucositis, the great majority of authors agree that adhesion to oral hygiene measures can reduce the duration and severity of OM (12), as well as help prevent the development of dental problems during the cancer treatment cycles.

The rest of the interventions showed no evidence of benefit, either due to methodological shortcomings of the trials, or because of contradicting results.

Our conclusions coincide with the guidelines the Multinational Association of Supportive Care in Cancer (MASCC) and the International Society of Oral Oncology (ISOO), which were updated in 2012 through several review articles $(15,22,29,40)$.

In sum, at present no concrete intervention may be regarded as the gold standard for the prevention and/ or treatment of oral mucositis, and we therefore must resort to recommendations based on the documented evidence. This indicates the need for increasing the methodological quality and number of clinical trials with 
the aim of expanding the scientific evidence supporting the different interventions. In this context, clinical trials should be carried out following the norms established by the CONSORT (Consolidated Standards of Reporting Trials) declaration, and including sufficient patients and subgroups in accordance to the type of chemotherapeutic agent involved. On the other hand, we consider it very important to unify criteria regarding the use of a single mucositis severity grading system, since this would facilitate comparisons among the different studies. In this respect, we recommend use of the scale developed by the WHO (grades 0-4) (Table 1).

\section{References}

1. Scully C, Epstein J, Sonis S. Oral mucositis: a challenging complication of radiotherapy, chemotherapy, and radiochemotherapy. Part 2: diagnosis and management of mucositis. Head Neck. 2004;26:77-84. 2. Stokman MA, Spijkervet FK, Boezen HM, Schouten JP, Roodenburg JL, de Vries EG. Preventive intervention possibilities in radiotherapy- and chemotherapy-induced oral mucositis: results of metaanalyses. J Dent Res. 2006;85:690-700.

3. Rodriguez-Caballero A, Torres-Lagares D, Robles-Garcia M, Pachon-Ibañez J, Gonzalez-Padilla D, Gutierrez-Perez JL. Cancer treatment-induced oral mucositis: a critical review. Int J Oral Maxillofac Surg. 2012;41:225-38.

4. Sonis ST, Elting LS, Keefe D, Peterson DE, Schubert M, HauerJensen M, et al. Perspectives on cancer therapy-induced mucosal injury: pathogenesis, measurement, epidemiology, and consequences for patients. Cancer. 2004;100:1995-2025.

5. Hernández-Fernández A, Oñate-Sánchez RE, Cabrerizo-Merino MC, de Arriba-de la-Fuente F, Heras-Fernando I, Vicente-García V. Influence of oral health on mucositis in patients undergoing hematopoietic progenitor cell transplantation (HPCT). Med Oral Patol Oral Cir Bucal. 2012;17:e94-e101.

6. Rubenstein EB, Peterson DE, Schubert M, Keefe D, McGuire D, Epstein J, et al. Clinical practice guidelines for the prevention and treatment of cancer therapy-induced oral and gastrointestinal mucositis. Cancer. 2004;100:2026-46.

7. Bjordal JM, Bensadoun RJ, Tunèr J, Frigo L, Gjerde K, Lopes-Martins RA. A systematic review with meta-analysis of the effect of lowlevel laser therapy (LLLT) in cancer therapy-induced oral mucositis. Support Care Cancer. 2011;19:1069-77.

8. Sabater Recolons Mdel M, López López J, Rodríguez de Rivera Campillo ME, Chimenos Küstner E, Conde Vidal JM. Buccodental health and oral mucositis. Clinical study in patients with hematological diseases. Med Oral Patol Oral Cir Bucal. 2006;11:E497-502.

9. López-Castaño F, Oñate-Sánchez RE, Roldán-Chicano R, Cabrerizo-Merino MC. Measurement of secondary mucositis to oncohematologic treatment by means of different scale. Review. Med Oral Patol Oral Cir Bucal. 2005;10:412-21.

10. Harris DJ, Eilers J, Harriman A, Cashavelly BJ, Maxwell C. Putting evidence into practice: evidence-based interventions for the management of oral mucositis. Clin J Oncol Nurs. 2008;12:141-52.

11. NHMRC. A Guide to the Development, Implementation and Evaluation of Clinical Practice Guidelines. Canberra: NHMRC. http:// www.nhmrc.gov.au/ files nhmrc/publications/attachments/cp30.pdf

12. McGuire DB, Correa ME, Johnson J, Wienandts P. The role of basic oral care and good clinical practice principles in the management of oral mucositis. Support Care Cancer. 2006;14:541-7.

13. Keefe DM, Schubert MM, Elting LS, Sonis ST, Epstein JB, RaberDurlacher JE, et al. Updated clinical practice guidelines for the prevention and treatment of mucositis. Cancer. 2007;109:820-31.

14. Nashwan AJ. Use of chlorhexidine mouthwash in children receiving chemotherapy: a review of literature. J Pediatr Oncol Nurs. 2011;28:295-9.
15. Nicolatou-Galitis O, Sarri T, Bowen J, Di Palma M, Kouloulias VE, Niscola P, et al. For The Mucositis Study Group of the Multinational Association of Supportive Care in Cancer/International Society of Oral Oncology (MASCC/ISOO). Systematic review of amifostine for the management of oral mucositis in cancer patients. Support Care Cancer. 2012.

16. Buentzel J, Micke O, Adamietz IA, Monnier A, Glatzel M, de Vries A. Intravenous amifostine during chemoradiotherapy for head-andneck cancer: a randomized placebo-controlled phase III study. Int J Radiat Oncol Biol Phys. 2006;64:684-91.

17. Nottage M, McLachlan SA, Brittain MA, Oza A, Hedley D, Feld $\mathrm{R}$, et al. Sucralfate mouthwash for prevention and treatment of 5-fluorouracil-induced mucositis: a randomized, placebo-controlled trial. Support Care Cancer. 2003;11:41-7.

18. Pytlik R, Benes P, Patorkova M, et al. Standardized parenteral alanyl-glutamine dipeptide supplementation is not beneficial in autologous transplant patients: a randomized, double-blind, placebo controlled study. Bone Marrow Transplant. 2002;30:953-61.

19. Cerchietti LC, Navigante AH, Lutteral MA, Castro MA, Kirchuk $\mathrm{R}$, Bonomi M, et al. Double-blinded, placebocontrolled trial on intravenous L-alanyl-L-glutamine in the incidence of oral mucositis following chemoradiotherapy in patients with head-and-neck cancer. Int J Radiat Oncol Biol Phys. 2006;65:1330-7.

20. Sornsuvit C, Komindr S, Chuncharunee S, Wanikiat P, Archararit N, Santanirand P. Pilot Study: effects of parenteral glutamine dipeptide supplementation on neutrophil functions and prevention of chemotherapy induced side-effects in acute myeloid leukaemia patients. J Int Med Res. 2008;36:1383-91.

21. Panahi Y, Ala S, Saeedi M, Okhovatian A, Bazzaz N, Naghizadeh MM. Allopurinol mouth rinse for prophylaxis of fluorouracil-induced mucositis. Eur J Cancer Care. 2010;19:308-12.

22. Peterson DE, Ohrn K, Bowen J, Fliedner M, Lees J, Loprinzi C, et al. For the Mucositis Study Group of the Multinational Association of Supportive Care in Cancer/International Society of Oral Oncology (MASCC/ISOO). Systematic review of oral cryotherapy for management of oral mucositis caused by cancer therapy. Support Care Cancer. 2012.

23. Sorensen JB, Skovsgaard T, Bork E, Damstrup L, Ingeberg S. Double-blind, placebo-controlled, randomized study of chlorhexidine prophylaxis for 5-fluorouracil-based chemotherapy-induced oral mucositis with nonblinded randomized comparison to oral cooling (cryotherapy) in gastrointestinal malignancies. Cancer. 2008;112:1600-6. 24. Papadeas E, Naxakis S, Riga M, Kalofonos C. Prevention of 5-fluorouracil-related stomatitis by oral cryotherapy: a randomized controlled study. Eur J Oncol Nurs. 2007;11:60-5.

25. Nikoletti S, Hyde S, Shaw T, Myers H, Kristjanson LJ. Comparison of plain ice and flavoured ice for preventing oral mucositis associated with the use of 5 fluorouracil. J Clin Nurs. 2005;14:750-3.

26. Gori E, Arpinati M, Bonifazi F, Errico A, Mega A, Alberani F, et al. Cryotherapy in the prevention of oral mucositis in patients receiving low-dose methotrexate following myeloablative allogeneic stem cell transplantation: a prospective randomized study of the Gruppo Italiano Trapianto di Midollo Osseo nurses group. Bone Marrow Transplant. 2007;39:347-52.

27. Lilleby K, Garcia P, Gooley T, McDonnnell P, Taber R, Holmberg $\mathrm{L}$, et al. A prospective, randomized study of cryotherapy during administration of high-dose melphalan to decrease the severity and duration of oral mucositis in patients with multiple myeloma undergoing autologous peripheral blood stem cell transplantation. Bone Marrow Transplant. 2006;37:1031-5.

28. Svanberg A, Birgegard G, Ohrn K. Oral cryotherapy reduces mucositis and opioid use after myeloablative therapy--a randomized controlled trial. Support Care Cancer. 2007;15:1155-61.

29. Raber-Durlacher JE, von Bültzingslöwen I, Logan RM, Bowen J, Al-Azri AR, Everaus H, et al. For the Mucositis Study Group of the Multinational Association of Supportive Care in Cancer/International Society of Oral Oncology (MASCC/ISOO). Systematic review of cytokines and growth factors for the management of oral mucositis in cancer patients. Support Care Cancer. 2012. 
30. Spielberger R, Stiff P, Bensinger W, Gentile T, Weisdorf D, Kewalramani $\mathrm{T}$, et al. Palifermin for oral mucositis after intensive therapy for hematologic cancers. N Engl J Med. 2004;351:2590-8.

31. Blazar BR, Weisdorf DJ, Defor T, Goldman A, Braun T, Silver S, et al. Phase $1 / 2$ randomized, placebo-control trial of palifermin to prevent graft-versus-host disease (GVHD) after allogeneic hematopoietic stem cell transplantation (HSCT). Blood. 2006;108:3216-22.

32. Brizel DM,Murphy BA, Rosenthal DI, Pandya KJ, Gluck S, Brizel HE, et al.Phase II study of palifermin and concurrent chemoradiation in head and neck squamous cell carcinoma. J Clin Oncol. 2008:26:2489-96

33. Henke M, Alfonsi M, Foa P, Giralt J, Bardet E, Cerezo L, et al. Palifermin decreases severe oral mucositis of patients undergoing postoperative radiochemotherapy for head and neck cancer: a randomized, placebo-controlled trial. J Clin Oncol. 2011;29:2815-20.

34. Le QT, Kim HE, Schneider CJ, Murakozy G, Skladowski K, Reinisch $\mathrm{S}$, et al. Palifermin reduces severe mucositis in definitive chemoradiotherapy of locally advanced head and neck cancer: a randomized, placebo-controlled study. J Clin Oncol. 2011;29:2808-14.

35. Meropol NJ, Somer RA, Gutheil J, Pelley RJ, Modiano MR, Rowinsky EK, et al. Randomized phase I trial of recombinant human keratinocyte growth factor plus chemotherapy: potential role as mucosal protectant. J Clin Oncol. 2003;21:1452-8.

36. Rosen LS, Abdi E, Davis ID, Gutheil J, Schnell FM, Zalcberg J, et al.Palifermin reduces the incidence of oral mucositis in patients with metastatic colorectal cancer treated with fluorouracil-based chemotherapy. J Clin Oncol. 2006;24:5194-200.

37. Vadhan-Raj S, Trent J, Patel S, Zhou X, Johnson MM, Araujo D, et al. Single-dose palifermin prevents severe oral mucositis during multicycle chemotherapy in patients with cancer: a randomised trial. Ann Intern Med. 2010;153:358-67.

38. Dazzi C, Cariello A, Giovanis P, Monti M, Vertogen B, Leoni M, et al. Prophylaxis with GM-CSF mouthwashes does not reduce frequency and duration of severe oral mucositis in patients with solid tumors undergoing high-dose chemotherapy with autologous peripheral blood stem cell transplantation rescue: a double blind, randomized, placebocontrolled study. Ann Oncol. 2003;14:559-63.

39. Valcarcel D, Sanz MA Jr, Sureda A, Sala M, Munoz L, Subira M, et al. Mouth-washings with recombinant human granulocyte-macrophage colony stimulating factor (rhGM-CSF) do not improve grade III-IV oropharyngeal mucositis $(\mathrm{OM})$ in patients with hematological malignancies undergoing stem cell transplantation. Results of a randomized double-blind placebo-controlled study. Bone Marrow Transplant. 2002;29:783-7.

40. Migliorati C, Hewson I, Lalla RV, Antunes HS, Estilo CL, Hodgson B, et al.; For the Mucositis Study Group of the Multinational Association of Supportive Care in Cancer/International Society of Oral. Systematic review of laser and other light therapy for the management of oral mucositis in cancer patients. Support Care Cancer. 2012.

41. Schubert MM, Eduardo FP, Guthrie KA et al. A phase III randomized double-blind placebo-controlled clinical trial to determine the efficacy of low level laser therapy for the prevention of oral mucositis in patients undergoing hematopoietic cell transplantation. Support Care Cancer. 2007;15:1145-54.

42. Antunes HS, de Azevedo AM, da Silva Bouzas LF, Adao CA, Pinheiro CT, Mayhe R, et al. Low-power laser in the prevention of induced oral mucositis in bone marrow transplantation patients: a randomized trial. Blood. 2007;109:2250-5.

43. Cruz LB, Ribeiro AS, Rech A, Rosa LG, Castro CG Jr, Brunetto $\mathrm{AL}$, et al. Influence of low-energy laser in the prevention of oral mucositis in children with cáncer receiving chemotherapy. Pediatr Blood Cancer. 2007;48(4):435-40.

44. Gouvea de Lima A, Villar RC, De Castro G Jr, et al. Oral mucositis prevention by low-level laser therapy in head-and-neck cancer patients undergoing concurrent chemoradiotherapy: a phase III randomized study. Int J Radiat Oncol Biol Phys. 2012;82:270-5.

45. Genot-Klastersky MT, Klastersky J, Awada F, Awada A, Crombez $\mathrm{P}$, Martinez MD, et al. The use of low-energy laser (LEL) for the prevention of chemotherapy- and/or radiotherapy-induced oral mucositis in cancer patients: results from two prospective studies. Supportive Care Cancer. 2008;16:1381-7.
46. Kuhn A, Porto FA, Miraglia P, Brunetto AL. Low level infrared laser therapy in chemotherapy-induced oral mucositis: a randomized placebo-controlled trial in children. J Pediatr Hematol Oncol. 2009; 31:33-7.

47. Worthington HV, Clarkson JE, Bryan G, Furness S, Glenny AM, Littlewood A, et al. Interventions for preventing oral mucositis for patients with cancer receiving treatment. Cochrane Database Syst Rev. 2011;13:CD000978.

48. Clarkson JE, Worthington HV, Furness S, McCabe M, Khalid T, Meyer S. Interventions for treating oral mucositis for patients with cancer receiving treatment. Cochrane Database Syst Rev. 2010;4:CD001973.

\section{Conflicts of interest}

The author denies any conflicts of interest related to this study. 